\title{
THE STUDY OF PHENOLIC COMPOUNDS IN CANNA LILY FLOWERS USING HPLC
}

\author{
Svetlana Tymofieieva, Oleksandra Kyslychenko, Iryna Zhuravel
}

National University of Pharmacy, Kharkiv, Ukraine

\begin{abstract}
Aim: The purpose of our work was the research of phenolic compounds in canna lily (Canna $x$ hybrida Hort.) flowers for a further detailed study of the phytochemical composition of raw material from the canna lily plant.

Materials and Methods: Canna lily flowers of red color collected in Ukraine in the summer seasons of the period 2014-2016 were chosen as the object of the study. Ethanol extracts obtained from dried flowers were used for the research. The extracts were analyzed using the high-performance liquid chromatography (HPLC) technique on a liquid chromatograph equipped with a diode-array detector Shimadzu HPLC-system, ser. 20. HPLC was used to detect phenolic compounds in canna lily flowers.

Results and Conclusion: Rutin, neochlorogenic, chlorogenic, caffeic and rosemarinic acids were identified in canna lily flowers.

The obtained experimental data can be used in the development of the standardization parameters of canna lily flowers.
\end{abstract}

Keywords: canna lily, rutin, neochlorogenic acid, chlorogenic acid, caffeic acid, rosemarinic acid, high performance liquid chromatography

\section{INTRODUCTION}

Carrying out studies of plants used in traditional medicine, which have vast raw material base, is important in order to expand the range of medicinal plant raw material at the modern pharmaceutical market.

Canna lily is one of these plants.

Address for correspondence:

Svetlana Tymofeeva

National University of Pharmacy

53 Pushkins'ka St

61000 Kharkiv

Ukraine

e-mail: svetlana.timofeeva@gmail.com

Received: June 7, 2017

Accepted: May 30, 2018
Canna lily is not an officinal plant in Ukraine. Nevertheless, canna lily is a prospective plant for a complex pharmacognostic study and further creation of new phytochemical remedies on its basis due to the diverse composition of biologically active compounds in its content.

From the literature it is known that other members of the Cannaceae family (including Canna indica L.) have been widely used in folk medicine as anti-inflammatory, immunomodulatory, antioxidant, antidiabetic, anticancer agents for a long time $(1,2)$. Phenolic biologically active substances correspond with these types of activity (3-5). Hydroxycinnamic acids and flavonoids, including a flavonoid glycoside rutin, also show these types of pharmacological action (3,6-9). Therefore a study of phenolic compounds in canna lily flowers is a basis for their further implementation in medical practice. 
The Study of Phenolic Compounds in Canna Lily Flowers Using HPLC

\section{AIM}

The purpose of this work was a study of phenolic compounds in canna lily flowers for a more detailed research on phytochemical composition of canna lily plant raw material.

\section{MATERIALS AND METHODS \\ Ethanol extract preparation:}

The determination was carried out by the highperformance liquid chromatography (HPLC) technique applying the following protocol: $0.50 \mathrm{~g}$ (exact weight) of the minced plant raw material was put into a 100-ml conical flask with reflux condenser followed by the addition of $25 \mathrm{ml}$ of $50 \%$ ethanol. The flask was left in a boiling water bath for $45 \mathrm{~min}$. After this the extract was cooled to room temperature and was filtered through the "red stripe" filter into a volumetric flask with a volume of $25 \mathrm{ml}$. The extract volume was adjusted till the mark with 50\% ethanol. The chromatographic determination of phenolic compounds was carried out on a liquid chromatograph equipped by diode-array detector Shimadzu HPLC-system, ser.20 in the following conditions: Phenomenex Luna C18(2) column. Column size was $250 \mathrm{~mm} \times 4.6 \mathrm{~mm}$ with particle size of $5 \mu \mathrm{m}$ and column temperature $-350^{\circ} \mathrm{C}$. The detection wavelength equaled $330 \mathrm{~nm}$, mobile phase flow rate was $1 \mathrm{ml} / \mathrm{min}$; the introduced sample volume was $5 \mu$ l. The mobile phase was the following: Chromatography time (min) Eluent A, \% Eluent B, \% 0-5 95 5 5-35 95 $\rightarrow 755 \rightarrow 2535-407525$ $40-6075 \rightarrow 5025 \rightarrow 5060-6550 \rightarrow 2050 \rightarrow 8065-70$ $208070-8595$ 5; Eluent A: 0.1\% solution of trifluoroacetic acid in water; Eluent B: $0.1 \%$ solution of trifluoroacetic acid in acetonitrile. Identification of components was carried out by retention time and UV spectra comparison in accordance with standards.

\section{RESULTS AND DISCUSSION}

According to the analysis results, rosemarinic, gallic and caffeic acids were identified with the help of HPLC. Their content was determined in the samples of canna lily plant raw material. The result of the study is presented in Figure 1 and Table 2.

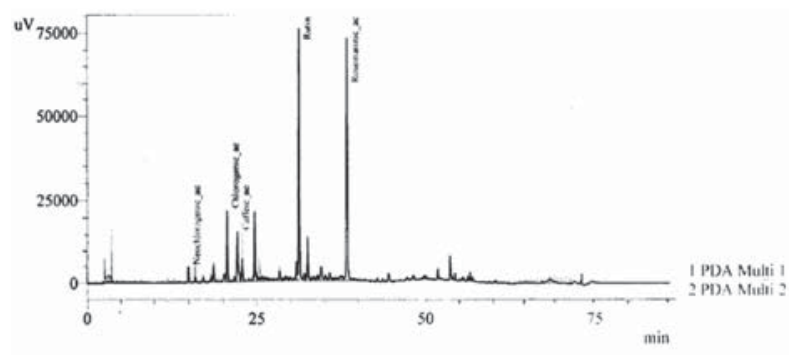

Fig. 1. Chromatogram of the phenolic compounds of canna lily flowers without hydrolysis

Table 1. Mobile phase

\begin{tabular}{lccc} 
Time, minutes & $\begin{array}{c}\text { Mobile phase A, \% } \\
\text { (turnover/turnover) }\end{array}$ & $\begin{array}{c}\text { Mobile phase B, \% } \\
\text { (turnover/turnover) }\end{array}$ & Mode \\
$0 \rightarrow 1$ & 92 & 8 & isocratic \\
$1 \rightarrow 15$ & $92 \rightarrow 70$ & $8 \rightarrow 30$ & gradient \\
$15 \rightarrow 25$ & $70 \rightarrow 0$ & $30 \rightarrow 100$ & gradient \\
$25 \rightarrow 33$ & 0 & 100 & isocratic \\
$33 \rightarrow 33.5$ & $0 \rightarrow 92$ & $100 \rightarrow 8$ & gradient \\
\hline
\end{tabular}

Table 2. Phenolic compounds' content in canna lily plant raw material

\begin{tabular}{cccc|c|c} 
№ & Retention time, min & Phenolic acids & Formula & $\begin{array}{c}\text { Molecular mass } \\
\mathrm{g} / \mathrm{mol}\end{array}$ & $\begin{array}{c}\text { Content in a studied } \\
\text { sample, \% }\end{array}$ \\
\hline 1 & 14.950 & Neochlorogenic acid & C16H18O9 & 354.31 & Trace amount \\
2 & 20.647 & Chlorogenic acid & C16H18O9 & 354.31 & 0.0367 \\
3 & 22.164 & Caffeic acid & C9H8O4 & 180.16 & 0.0204 \\
5 & 38.270 & Rosemarinic acid & C18H16O8 & 360.31 & 0.1409 \\
4 & 31.200 & Rutin & C27H30O16 & 610.52 & 0.2415 \\
\hline \hline
\end{tabular}


Svetlana Tymofieieva, Oleksandra Kyslychenko, Iryna Zhuravel

Rutin, neochlorogenic, chlorogenic, caffeic and rosemarinic acids were identified in canna flowers. Rutin was a dominant compound among detected phenolic compounds. Its content equaled $0.2415 \pm 0.0100 \%$. Rosemarinic acid was a dominant component among the determined phenolic acids. Its content equaled $0.1409 \pm 0.0200 \%$. Chlorogenic and caffeic acids were found in smaller amounts and their content was $0.0367 \pm 0.0100 \%$ and $0.0204 \pm 0.0100 \%$, respectively. Only trace amounts of neochlorogenic acid were found.

\section{CONCLUSION}

Currently, there is an increasing demand for drugs obtained from medicinal plant raw material in the pharmaceutical market of Ukraine as well as abroad.

The conducted study allows the development standardization methods for canna lily plant raw material according to the following data:

1. Five phenolic compounds, such as rutin, neochlorogenic, chlorogenic, caffeic and rosemarinic acids were determined in canna lily flowers by the HPLC technique.

2. Rutin dominated by content the other phenolic compounds identified. Its amount equaled $0.2415 \pm 0.0100 \%$.

3. Rosemarinic acid was a dominant component by content among the phenolic acids determined. Its content equaled $0.1409 \pm 0.0200 \%$. Chlorogenic and caffeic acids were found in smaller amounts and their content was $0.0367 \pm 0.0100 \%$ and $0.0204 \pm 0.0100 \%$, respectively. Only trace amounts of neochlorogenic acid were found.

4. The obtained experimental data can be used in the development of standardization parameters for canna lily flowers as well as for the subsequent development of substances from the analyzed plant raw material.

\section{REFERENCES}

1. Al-Snafi AE. Bioactive components and pharmacological effects of Canna indica - an overview. Int J Pharmacol Toxicol. 2015;5(2):71-5.

2. Srivastava J, Vankar PS. Canna indica flower: New source of anthocyanins. Plant Physiol Biochem. 2010;48(12):1015-9. doi: 10.1016/j. plaphy.2010.08.011.
3. Abdullah Y, Schneider B, Petersen M. Occurrence of rosmarinic acid, chlorogenic acid and rutin in Marantaceae species. Phytochem Lett. 2008;1(4):199-203. doi: 10.1016/j.phytol.2008.09.010.

4. Vankar PS, Jyoti S. Comparative study of total phenol, flavonoid contents and antioxidant activity in Canna indica and Hibiscus rosa sinensis: Prospective natural food dyes. Int J Food Eng. 2008;4(3):115. doi: 10.2202/1556-3758.1232.

5. Mishra T, Goyal AK, Middha SK, Sen A. Antioxidative properties of Canna edulis Ker-Gawl. Indian J Nat Prod Resour. 2011; 2(3): 315-21.

6. Zhang J, Wang ZW, Mi Q. Phenolic compounds from Canna edulis Ker residue and their antioxidant activity. J Food Sci Technol. 2011; 44(10): 20916. doi: 10.1016/j.lwt.2011.05.021.

7. Sharma S, Ali A, Ali J, Sahni JK, Baboota S. Rutin: therapeutic potential and recent advances in drug delivery. Expert Opin Investig Drugs. 2013;22(8):1063-79. doi: 10.1517/13543784.2013.805744.

8. Habtemariam S, Varghese GK. Extractability of rutin in herbal tea preparations of Moringa stenopetala leaves. Beverages. 2015;1(3):169-82. doi:10.3390/beverages1030169.

9. Chua LS. A review on plant-based rutin extraction methods and its pharmacological activities. J Ethnopharmacol. 2013;150(3):805-17. doi: 10.1016/j. jep.2013.10.036. 